\title{
Dose-dependent effect of tamoxifen in tamoxifen-resistant breast cancer cells via stimulation by the ERK1/2 and AKT signaling pathways
}

\author{
LI-JUAN WANG $^{1}$, SU-XIA HAN $^{1}$, E BAI $^{1}$, XIA ZHOU $^{1}$, MENG LI $^{1}$, \\ GUI-HUA JING ${ }^{1}$, JING ZHAO ${ }^{1}$, AN-GANG YANG ${ }^{2}$ and QING ZHU $^{1}$ \\ ${ }^{1}$ Department of Oncology, The First Affiliated Hospital, College of Medicine, Xi'an Jiaotong University, \\ Xi'an 710061; ${ }^{2}$ Department of Immunology, the Fourth Military Medical University, Xi'an 710032, P.R. China
}

Received November 5, 2012; Accepted December 20, 2012

DOI: $10.3892 /$ or.2013.2245

\begin{abstract}
The majority of breast cancers undergo progression from an initially endocrine responsive phenotype to an endocrine therapy-resistant phenotype, and acquired resistance to tamoxifen (Tam) is a major clinical problem. In the present study, we aimed to identify the function and mechanism of Tam at different concentrations in cells with acquired Tam resistance. Estrogen-dependent MCF-7 cells were cultured with Tam to generate Tam-resistant (TAM-R) breast cancer cells or in estrogen-free medium to mimic the effects of clinical treatment. In addition, we analyzed the effects of different concentrations of Tam on TAM-R cells by cell counting. Furthermore, the crosstalk between the stimulatory G protein $\alpha$ subunit (Gas) and the activation of ERK1/2 and AKT in TAM-R cells was examined by small interfering RNA (siRNA) and immunoblotting methods. Low-dose Tam was found to act as an estrogen agonist via stimulation of the ERK1/2 signaling pathway, resulting in acquired resistance to Tam, whereas high-dose Tam inhibited TAM-R cell growth by blocking the activation of ERK1/2 and AKT. Moreover, Gas was involved in Tam resistance in breast cancer cells. Taken together, our study demonstrated a dose-dependent growth response to Tam in TAM-R cells, which will promote the understanding of the importance of the appropriate use and dosage of Tam in the clinic.
\end{abstract}

Correspondence to: Dr Qing Zhu, Department of Oncology, The First Affiliated Hospital, College of Medicine, Xi'an Jiaotong University, No. 277 Yanta West Road, Xi'an 710032, P.R. China

E-mail: newzhuqing1972@yahoo.com

Abbreviations: Tam, tamoxifen; ER, estrogen receptor; PR, progesterone receptor; TAM-R, tamoxifen-resistant; GPER, G proteincoupled estrogen receptor 1; GPR30, G protein-coupled receptor 30; EGFR, epidermal growth factor receptor; E2, 17 $\beta$-estradiol; RNAi, RNA interference; G $\alpha$ s, stimulatory G protein $\alpha$ subunit; FCS, fetal calf serum

Key words: tamoxifen, ERK1/2, AKT, Gas, Tam-resistant breast cancer cells

\section{Introduction}

Tamoxifen (Tam), a selective estrogen receptor (ER) modulator, is the most frequently used anti-hormonal drug for the treatment of both early and advanced ER-positive breast cancer in pre- and post-menopausal women. Studies concerning adjuvant therapy reveal that Tam significantly decreases recurrence and mortality in patients with ER-positive breast cancer and could make a great contribution to the reduction in the odds of breast cancer incidence in healthy women at an increased risk (1-3). De novo and acquired resistant to Tam remains a problems, and several reasons have been proposed to be responsible for the development of Tam resistance. The reduction or loss of ER signaling, the function of recently discovered $\mathrm{G}$ protein-coupled estrogen receptor 1 (GPER) also known as G protein-coupled receptor 30 (GPR30), quantitative or qualitative change in ER-related co-factors, overexpression of epidermal growth factor receptor (EGFR) can contribute to the development of endocrine-resistance in breast cancer (4-7). However, these studies have failed to focus on the dose-effect of Tam on the proliferation of Tam-resistant (TAM-R) cells.

To date, Tam has no effect on the proliferation of TAM-R cells derived from MCF-7 breast cancer cells by means of continuous Tam exposure (8). However, it has been proven that a relatively low concentration of Tam has a stimulated effect on the proliferation of TAM-R cells in vitro $(9,10)$, and can promote tumor growth in MCF-7/HER2-18 xenografts (11), in Tam-resistant animal models (12). More importantly, it has been confirmed that a high concentration of Tam $(\geq 10 \mu \mathrm{M})$ is able to inhibit TAM-R cell proliferation (10). Recently, Ward et al reported that exposure to $10 \mu \mathrm{M}$ Tam was sufficient to induce G1 arrest in both MCF-7 and TAM-R cells, which demonstrated the preserved sensitivity of TAM-R cells to Tam at a relatively high concentration (13). This evidence indicates that a relatively low concentration and a high concentration of Tam have specific effects on the proliferation of TAM-R cells.

In the present study, we investigated the differential effects of different concentrations of Tam on the proliferation of TAM-R cells, an issue that has not received sufficient attention in the past. We proposed that Tam treatment at a low concentration may not have beneficial effects on Tam-resistant breast 
cancer cells, instead it may promote cell growth. In addition, Tam treatment at a relatively high concentration has the ability to inhibit TAM-R cell proliferation in the experimental condition. Furthermore, we determined that different signaling pathways may account for this dose-effect of Tam in TAM-R cells.

\section{Materials and methods}

Cell culture and treatment. MCF-7 cells obtained from the American Type Culture Collection (ATCC, Manassas, VA, USA) were routinely cultured in RPMI-1640 media containing $5 \%$ fetal calf serum (FCS). Tam-resistant (TAM-R) cells were derived from MCF-7 cells by continuous culture in phenol-redfree media containing 5\% steroid-depleted FCS, $10^{-7} \mathrm{M}$ Tam and $0.1 \%$ ethanol. The media for control cells contained $0.1 \%$ ethanol. For all experiments, the cells were seeded in 6-well plates and cultured in phenol-red-free medium supplemented with $5 \%$ steroid-depleted FCS.

Isolation of primary tumor cells from pleural effusion. After obtaining informed consent, primary breast cancer cells were collected from pleural effusion of a patient diagnosed with breast carcinoma with liver and lung metastases [HER2(+++), $\mathrm{ER}(+), \mathrm{PR}(+)]$. Cells in the pleural fluid were diluted with DMEM, centrifuged, and the pellet was washed twice with PBS. Breast cancer cells were isolated to apply density gradient centrifugation using Percoll fluid. The freshly isolated primary breast cancer cells were resuspended in RPMI-1640 media with $5 \%$ fetal calf serum, $50 \mu \mathrm{g} / \mathrm{ml}$ penicillin and $100 \mu \mathrm{g} / \mathrm{ml}$ streptomycin.

RNA interference (RNAi). The following small-interfering RNA oligonucleotides were used for knockdown of the stimulatory $\mathrm{G}$ protein $\alpha$ subunit (Gas): sense, 5'-GGCGCAGCGUGAGGC CAACTT-3' and antisense, 5'-GUUGGCCUCACGCUGCG CCTT-3'. A random siRNA (5'-GUGUCUCCCAGUCCUG CGCCTT-3') was used as the control. The RNAi oligonucleotides were transfected into cells using Lipofectamine $2000^{\mathrm{TM}}$ (Invitrogen, Carlsbad, CA, USA) and all experiments were performed $48 \mathrm{~h}$ later.

Growth curves. MCF-7 and TAM-R cells were treated with various concentrations $(0 \mathrm{nM}, 10 \mathrm{nM}, 100 \mathrm{nM}, 1 \mu \mathrm{M}, 5 \mu \mathrm{M}$, $10 \mu \mathrm{M}, 15 \mu \mathrm{M}$ and $20 \mu \mathrm{M}$ ) of Tam or $17 \beta$-estradiol (E2) for 5 days, and the number of cells were counted using a cell counting chamber according to the manufacturer's instructions as previously described (10). The cell number was expressed as a percentage $(\%)$ of the control.

Immunoblotting. Total proteins were extracted using total protein mammalian cell lysis buffer, separated using $10 \%$ SDS-PAGE gels and transferred to nitrocellulose filter membranes. The membranes were blocked with $5 \%$ skimmed milk in Tris-buffered saline containing 0.1\% Tween-20 and incubated with primary antibodies overnight at $4^{\circ} \mathrm{C}$, followed by peroxidase-conjugated secondary antibodies for $2 \mathrm{~h}$ at room temperature. The bands were detected using enhanced chemiluminescence. The rabbit anti-Gas polyclonal antibody, anti- $\beta$-actin antibody and secondary antibodies were purchased from Abcam (Cambridge, UK), and the total and phosphorylated ERK1/2 and AKT antibodies, ER and EGFR antibodies were purchased from Bioworld Technology Inc. (Visalia, CA, USA).

Statistical analysis. Each experiment was repeated at least three times, and the results are expressed as means \pm SD. Statistical analysis was performed using the Student's t-test; $\mathrm{P}<0.05$ was considered to indicate a statistically significant result.

\section{Results}

Generation of TAM-R cells and dose-response of Tam. MCF-7 cells were continuously cultured in medium containing $10 \mathrm{nM}$ Tam dissolved in $0.1 \%$ ethanol for 6 months to generate a Tam-resistant (TAM-R) cell line. MCF-7 cells continuously cultured with $0.1 \%$ ethanol were used as controls. Since breast tumors are dependent on E2 for growth and Tam acts as an anti-estradiol drug to inhibit cell growth in vivo, the growth effect of Tam and E2 was tested. As expected, there was a difference in the proliferation rate between MCF-7 and TAM-R cells following treatment with $10 \mathrm{nM} \mathrm{E2}$. MCF-7 cells had a higher proliferation rate as measured by direct cell counting compared with the TAM-R cells (Fig. 1A). Exposure to $1 \mu \mathrm{M}$ Tam was sufficient to inhibit the proliferation of MCF-7 cells, thus many previous studies selected $1 \mu \mathrm{M}$ as the final concentration of Tam for their experiments. Compared with MCF-7 cells, the growth of TAM-R cells was inhibited completely by Tam at a high concentration $>10 \mu \mathrm{M}$, while low doses (10 nM-5 $\mu \mathrm{M})$ of Tam stimulated the growth of TAM-R cells; $1 \mu \mathrm{M}$ Tam promoted TAM-R cell growth most significantly (Fig. 1B). Overall, we identified the dose-response of Tam in TAM-R cells in our experiment.

Isolation of Tam-resistant primary breast cancer cells and the dose-effect of Tam. To further confirm the results shown in the above experiment, we isolated the primary breast cancer cell line shown in Fig. 2A from the pleural effusion of a patient following long-term use of Tam and diagnosed with breast carcinoma with liver and lung metastases [HER2 (+++), ER $(+)$, PR (+)]. The patient was diagnosed as Tam-resistant in the clinic (14). The acquired resistance to Tam was measured by dose-dependent growth assays. When primary breast cancer and MCF-7 cells were treated with Tam at increasing concentrations from $10 \mathrm{nM}$ to $20 \mu \mathrm{M}$, the survival ratios showed marked differences between the two cell lines. For example, at $10 \mathrm{nM}$ Tam, the cell growth was stimulated in the primary breast cancer cells, and this trend continued until the Tam concentration reached $10 \mu \mathrm{M}$ where the growth of primary breast cancer cells was blocked; however, at $1 \mu \mathrm{M}$ Tam, the proliferation of MCF-7 cells was markedly inhibited (Fig. 2B). Moreover, the proliferation responses of the primary breast cancer cells to Tam were similar to the TAM-R cells. Taken together, we conclude that there is a dose-dependent relationship between Tam and the growth responses of TAM-R cells.

Effect of a low-dose of Tam on the ERK1/2 and AKT signaling pathways in TAM-R cells. As the activation of the ERK1/2 and AKT kinase signaling pathways is thought to 
A

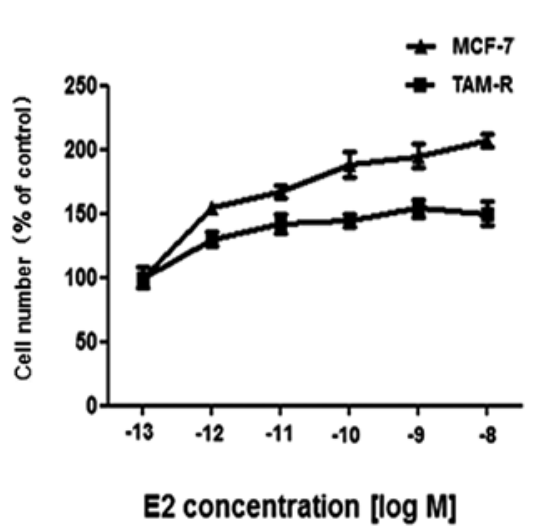

B

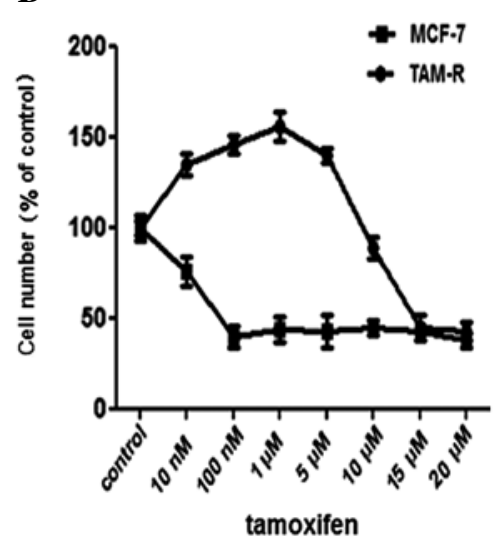

Figure 1. Effects of estrogen and tamoxifen on MCF-7 and TAM-R cell growth. Cells were treated with various concentrations of (A) E2 or (B) Tam, and the cell number was determined using a cell counting chamber after 5 days of treatment. Each experiment was repeated at least three times. Results are expressed as means $\pm \mathrm{SD}$.
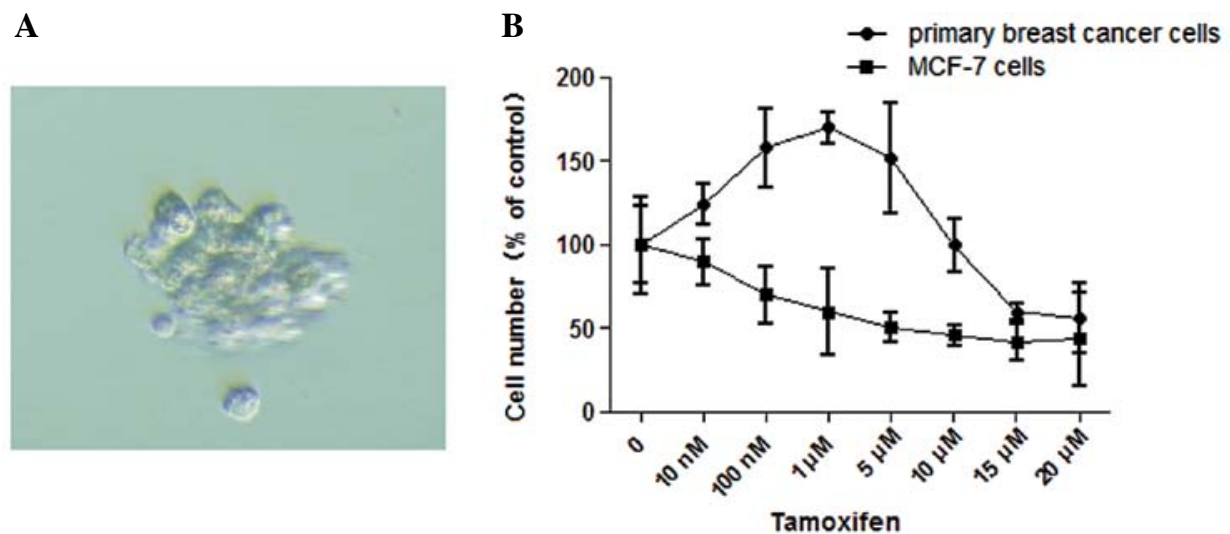

Figure 2. Isolation of tamoxifen-resistant primary breast cancer cells and dose-response of tamoxifen. (A) Primary human breast cancer cells. (B) Primary human breast cancer cells were treated with different concentrations of Tam, and the cell number was counted after 5 days. Results are expressed as means \pm SD of triplicate experiments.

be an important regulating factor $(8,11,15,16)$, we analyzed the ability of E2 and Tam to induce ERK1/2 and AKT phosphorylation in TAM-R and control MCF-7 cells. ERK1/2 phosphorylation increased in the TAM-R cells treated with $10 \mathrm{nM}$ E2 within 5-10 min and disappeared rapidly, whereas ERK1/2 phosphorylation was observed after $10 \mathrm{~min}$ and continued until $30 \mathrm{~min}$ in MCF-7 cells following $10 \mathrm{nM} \mathrm{E} 2$ treatment (Fig. 3A), which implied that E2 had a more lasting effect on MCF-7 cells than on TAM-R cells. Treatment with $1 \mu \mathrm{M}$ Tam resulted in a significant attenuation of ERK1/2 phosphorylation in MCF-7 cells, whereas $1 \mu \mathrm{M}$ Tam stimulated ERK1/2 phosphorylation within 5-20 min in TAM-R cells, in a similar manner to the effect of E2 on ERK1/2 phosphorylation in MCF-7 cells. This indicated that $1 \mu \mathrm{M}$ Tam may act as E2, to stimulate ERK1/2 phosphorylation in TAM-R cells (Fig. 3B). However, after treated with E2 or Tam, the phosphorylation level of AKT remained constant in the TAM-R cells as well as control MCF-7 cells (Fig. 3). These results demonstrated that low-dose Tam may act as an agonist, such as E2, to stimulate ERK1/2 phosphorylation and induce TAM-R cell proliferation, whereas AKT activity may be unrelated with the growth or survival of TAM-R cells in the presence of low-dose Tam.
High-dose Tam downregulates ERK1/2 and AKT activity in $T A M-R$ cells. In order to investigate whether high-dose and low-dose Tam have differential effects on ERK1/2 and AKT signaling pathways in TAM-R cells, we analyzed the phosphorylation of ERK1/2 and AKT induced following treatment with $15 \mu \mathrm{M}$ Tam. The activation of ERK1/2 was markedly and sustainably suppressed under this condition, which was different compared to treatment with $1 \mu \mathrm{M}$ Tam in TAM-R cells (Fig. 3B). In addition, the phosphorylation of AKT was inhibited in TAM-R cells following treatment with $15 \mu \mathrm{M}$ Tam for $10 \mathrm{~min}$ (Fig. 4); however, after exposure to $1 \mu \mathrm{M}$ Tam, the levels of p-AKT in the TAM-R cells barely changed (Fig. 3B). These results suggested that downregulation of $\mathrm{p}-\mathrm{ERK} 1 / 2$ and p-AKT was caused by high-dose Tam to inhibit TAM-R cell proliferation. Taken together, a dose-response effect of Tam was noted on TAM-R cell proliferation and different doses of Tam had differential effects on ERK1/2 and AKT signaling pathways in TAM-R cells; thus we hypothesized that different doses of Tam stimulate or inhibit TAM-R cell growth via different signaling pathways. and ERK1/2 phosphorylation in TAM-R cells. It has been 


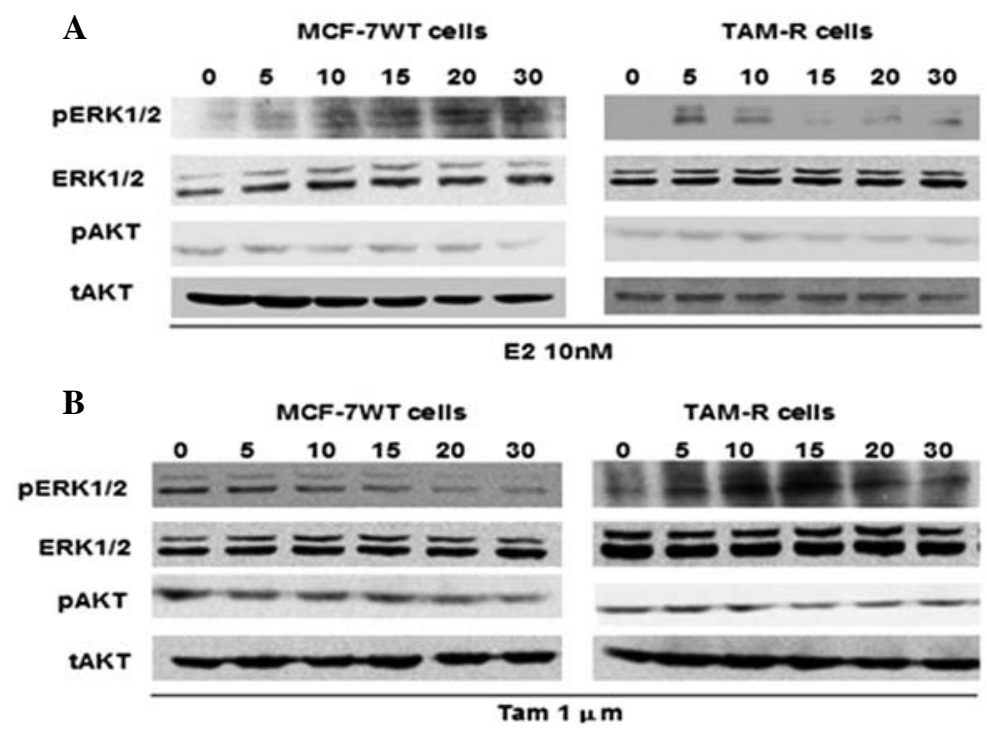

Figure 3. Effect of low-dose tamoxifen on the ERK1/2 and AKT signaling pathways in TAM-R cells. (A) MCF-7 and TAM-R cells were treated with $10 \mathrm{nM}$ $17 \beta$-estradiol (E2) for $0,5,10,15,20$ or $30 \mathrm{~min}$. (B) TAM-R and MCF-7 cells were treated with $1 \mu \mathrm{M}$ tamoxifen for $0,5,10,15,20$ or 30 min, and after the preparation of cell lysates, western blot analysis was performed. The expression of phosphorylated (p) or total (t) ERK1/2 and AKT proteins was examined by western blot analysis using specific antibodies.

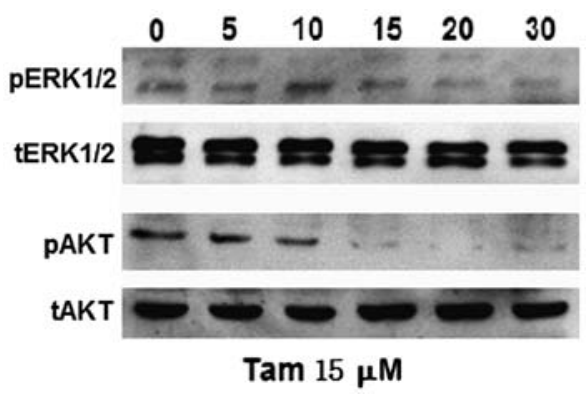

Figure 4. High-dose tamoxifen downregulates ERK1/2 and AKT activity in TAM-R cells. TAM-R cells were treated with $15 \mu \mathrm{M}$ tamoxifen (Tam) for $0,5,10,15,20$ or $30 \mathrm{~min}$, and after preparation of the cell lysates, western blot analysis was performed. The expression of phosphorylated (p) or total (t) ERK1/2 and AKT proteins was examined by western blot analysis using specific antibodies.

confirmed that the MEK/ERK pathway is involved in Tam resistance (15), and Gas stimulates MEK/ERK via the AC/cAMP/PKA pathway $(17,18)$. Therefore, we investigated whether Gas is involved in the activation of ERK induced by Tam at a low concentration and is related with Tam resistance in TAM-R cells. We used siRNA to silence the expression of Gas in TAM-R cells. Knockdown of Gas in TAM-R cells significantly enhanced the anti-proliferative activity of Tam (Fig. 5A). To investigate whether Gas is required for Tam-induced ERK1/2 and AKT phosphorylation in TAM-R cells, Gas RNAi oligonucleotides were used to knock down Gas in TAM-R cells. TAM-R cells were transfected with Gas RNAi oligonucleotides for $48 \mathrm{~h}$, and the cells were treated with $1 \mu \mathrm{M}$ Tam for $15 \mathrm{~min}$. As shown in Fig. 5B, silencing of Gas expression inhibited the ability of Tam to induce ERK1/2 phosphorylation but not AKT phosphorylation in TAM-R cells, when compared to the control cells. These results indicate that the ability of Tam to stimulate ERK1/2 phosphorylation in TAM-R cells was mediated by Gas.

\section{Discussion}

In the present study, we confirmed that different concentrations of Tam have opposite effects via different signaling pathways on the proliferation of TAM-R cells. Our results indicate that relatively low doses of Tam promote the proliferation of TAM-R cells by activation of ERK1/2. On the contrary, relatively high doses of Tam inhibit the proliferation of TAM-R cells by downregulating the phosphorylation of ERK1/2 and AKT. To our knowledge, this is the first study demonstrating the different mechanisms involved in the differential effects of high and low concentrations of Tam on TAM-R cells. These unexpected findings enrich the limited data concerning the effects of different doses of Tam on TAM-R cells, and provide a novel and helpful perspective to identify the molecular targets of high-dose Tam compared with a relatively low-dose Tam in TAM-R cells which was used to investigate the mechanism of Tam resistance in a previous study (19). Additionally, our observations not only identify the harmful effects of a low dose of Tam for the therapy of Tam-resistant patients but also provide a convenient and workable approach to overcome resistance to Tam.

Although much research has been focused on the mechanisms of Tam resistance in breast cancer (20-23), this issue still remains to be elucidated. In order to further elucidate this issue, and identify the role of Tam in TAM-R cells, we first tested the stability of TAM-R cells that were obtained after six months of screening $(10,24)$. In agreement with previous studies $(9-10,25,26)$, we found a Tam-stimulated growth effect in TAM-R cells after treatment with low-dose Tam, which implied that Tam at a low concentration may promote tumor growth in Tam-resistant patients. Nevertheless, the specific mechanism was only partially characterized; a possible reason for this phenomenon may be that Tam at a low concentration plays an estrogen-like role in this process.

At standard dosages, Tam has minimal or no effect on Tam-resistant breast cancer cells (27). At higher concentrations of Tam beyond the dose that promotes tumor growth 
A

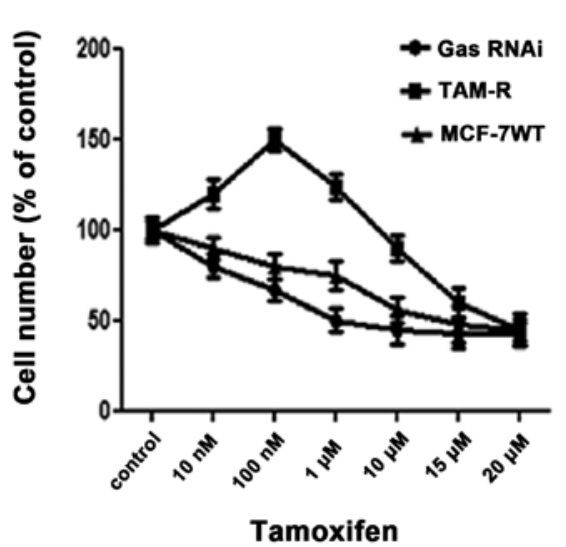

B
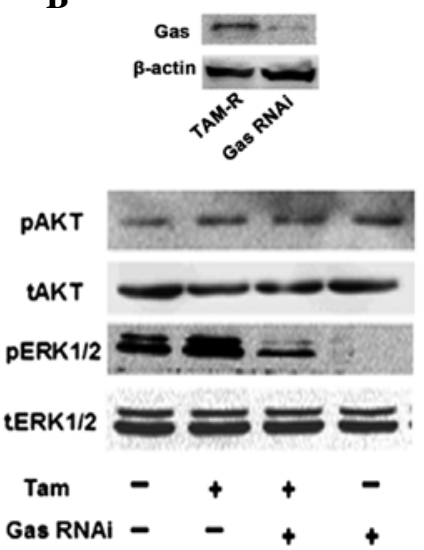

Figure 5. Gas knockdown alters proliferation responses and ERK1/2 phosphoralition of Tam in TAM-R cells. (A) TAM-R cells were transfected with Gas RNAi oligonucleotides. After $24 \mathrm{~h}$, the cells were treated with various concentrations of tamoxifen, and the cell number was counted after 5 days. Results are expressed as mean \pm SD of triplicate experiments; ${ }^{* *} \mathrm{P}<0.01$, Student's t-test. (B) After the transfection of TAM-R cells with Gas RNAi oligonucleotides for $48 \mathrm{~h}$, the cells were lysed and analyzed by western blotting using antibodies against Gas and $\beta$-actin. The level of Gas was reduced to <50\% of the control levels in the cells transfected with oligos specific for Gas. Furthermore, the cells transfected with Gas RNAi oligonucleotides and the control cells were treated with $1 \mu \mathrm{M}$ Tam for $10 \mathrm{~min}$. After preparation of the cell lysates, western blot analysis was performed. The expression of phosphorylated (p) or total (t) ERK1/2 and AKT proteins was examined by western blot analysis using specific antibodies.

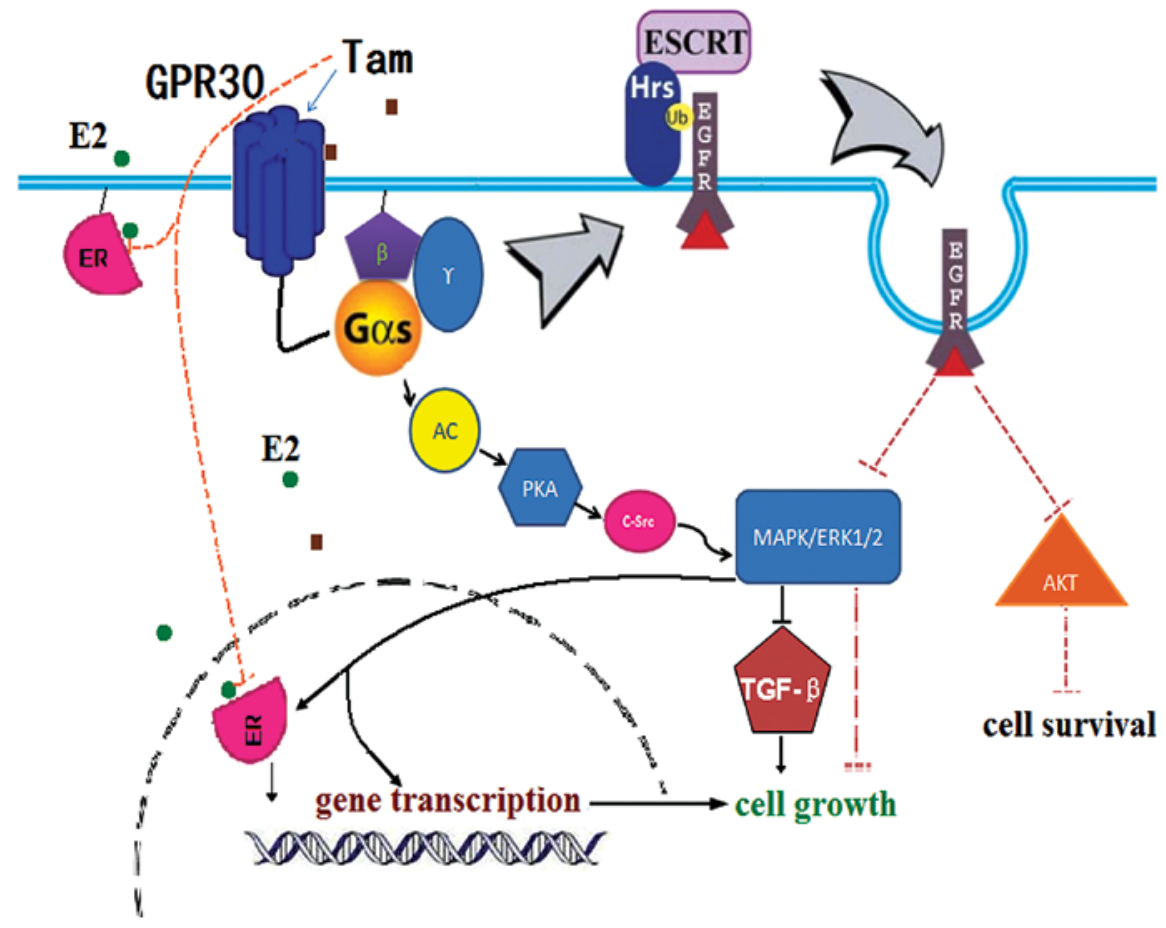

Figure 6. A mechanistic model of Gas-mediated differential signaling pathways in TAM-R cells. The proposed mechanistic model is based on the known signaling properties and abilities of various signaling components to regulate cell proliferation and survival. In TAM-R cells, GPR30 is upregulated by E2 and its recruitment and translocation from endoplasmatic reticulum to the cell surface increases $(28,29)$. Tam binds to GPR30 as an agonist and stimulates Gas/ ERK1/2 signaling to induce cell growth via the AC/cAMP/PKA signaling pathway. On the other hand, activated Gas increases the degradation of EGFR (36), which is essential for cell growth and survival (33-35). The degradation of EGFR directly decreases the activation of ERK1/2 and AKT, and cell growth is inhibited. Under a condition of low-dose Tam, the former function has a dominant advantage, thus the overall effect of Tam is to stimulate the phosphorylation of ERK1/2 and induce cell growth. With an increase in the concentration of Tam, the latter inhibitory effect is far stronger than the role of the former. Therefore, the activation of ERK1/2 and AKT is blocked and cell growth is inhibited.

most effectively, we found that the growth-promoting effect of Tam decreased accordingly, with gradually increasing concentrations of Tam. However, when the concentration of Tam reached a certain high value, Tam exerted an inhibitory effect on the proliferation of TAM-R cells. Leung et al reported that high-dose Tam did not function to block TAM-R cell proli- feration (28), while our data challenged the traditional view on the role of Tam. The results from our experiments suggest that Tam at a high concentration still has an inhibitory effect on the proliferation of TAM-R cells. In order to provide further evidence for our unexpected results, we collected the pleural effusion of a patient with advanced breast cancer recurrence 
and metastasis, who underwent long-term use of Tam and had been diagnosed as Tam resistant in the clinic (14). We treated the primary breast cancer cells isolated from the pleural effusion of the Tam-resistant patient with different concentrations of Tam. As expected, similar effects of Tam at different concentrations on the proliferation of primary TAM-R cells were observed (Fig. 2B). Taken together, Tam may still exhibit complicated yet significant effects on tumor growth after Tam resistance is abrogated in breast tumors.

Studies have shown that high ERK1/2 or Akt activity in breast carcinoma is associated with a poor patho-phenotype, as well as hormone and Tam resistance $(8,11,15,16)$. Moreover, Tam at a low concentration is suggested to have an estrogenlike role in TAM-R cells (10). We assayed the effects of E2 and Tam on the phosphorylation of ERK1/2 and AKT in TAM-R and control cells. We found that Tam at $1 \mu \mathrm{M}$, similar to estrogen, induced phosphorylation of ERK1/2 in Tam-R cells; however, it behaved as an antagonist in the parental cells. However, to our surprise, the phosphorylation level of AKT remained constant in TAM-R cells as well as control cells after being induced with E2 and $1 \mu \mathrm{M}$ Tam. Our data suggest that the activation of AKT is not involved in the function of a low concentration of Tam as an agonist in the proliferation of TAM-R cells. This is not consistent with previous studies that found the phosphorylation of AKT as an important element in the proliferation of TAM-R cells $(8,29)$.

Gas stimulates MEK/ERK via the AC/cAMP/PKA pathway $(17,18)$. Therefore, we investigated whether Gas is involved in Tam resistance in TAM-R cells. We found that Tam failed to activate the phosphorylation of ERK1/2, and that Tam at a low concentration inhibited the proliferation of TAM-R cells significantly after knockdown of Gas expression. Thus, Gas is involved in the Tam resistance in TAM-R cells and should be a prerequisite for Tam at a low concentration regarding its estrogen-like effect on TAM-R cells. In addition, research has now demonstrated that there exists a cross-communication between GPR30 and the development of breast cancer resistance in response to Tam (30-32). Tam not only has high binding affinities to GPR30, but also mimicks the actions of E2 to stimulate cell growth (33). Tam binding to GPR30 induced MAPK/ERK1/2 phosphorylation via $G$ protein and suppressed TGF- $\beta$ signaling to promote cell proliferation (34). Tam at a low concentration was found to promote the proliferation of TAM-R cells through the above-mentioned pathway.

In addition, many studies have confirmed that overexpression of EGFR or the aberrant activation of the EGFR signaling pathways are responsible for Tam-resistance $(35,36)$. Activated Gas promotes the degradation of EGFR $(37,38)$, which reduces the expression of EGFR and blocks the EGFR signaling pathways indirectly, and then inhibits cell growth. Thus, consistently overactive Gas inhibits the proliferation of TAM-R cells by promoting the degradation of EGFR. Combined with our results, we provide an explanation for the estrogen-like activity of low-dose Tam in TAM-R cells and why high-dose Tam inhibits TAM-R cell proliferation (Fig. 6). In TAM-R cells, the sensitivity of ER to Tam decreases, and the expression of GPR30 is upregulated (39). Therefore, Tam at a low concentration can promote the proliferation of TAM-R cells by further upregulating the expression and activation of GPR30. However, in this case, Gas is consistently overactive when GPR30 binds to high-dose Tam, and then continuous activation of Gas promotes the degradation of EGFR, whose expression decreases quickly and obviously. The degradation of EGFR results in the arrest of the activation of ERK1/2 and AKT directly, which has an inhibitory effect on the proliferation of TAM-R cells. When the inhibitory effect of overactive Gas which induces EGFR degradation overrides the stimulating effect on proliferation via GPR30, the growth of TAM-R cells is blocked. This hypothesis will provide answers to whether the estrogen-like effect of low-dose Tam or Tam at a high concentration inhibits the proliferation of TAM-R cells via suppression of the activation of ERK1/2 and AKT.

The controversy concerning a standardized guideline for Tam dosage has not been reached, and the mechanism of Tam resistance is still partially characterized. Although we have not yet acquired a large-scale epidemiological survey of the outcome of different doses of Tam, there is no doubt that our data will help to promote the appropriate clinical application of Tam and elucidate the mechanism of Tam resistance. We identified the dose-effects of different doses of Tam in the therapy of breast cancer especially TAM-R breast cancer. We also provide a new insight into the study of the mechanism of Tam resistance. However, the mechanisms responsible for the dose-response of Tam and the reason for differences in the survival rates of patients treated with different dosages of Tam need further elucidation.

Many studies have shown that the compliance to Tam dosage has a close relationship with the survival rate of breast cancer patients (40). According to our results, we hypothesized that patients with an irregular medication schedule have a poor survival rate as the drug concentration in blood fails to maintain a relatively high level, and a low dose of Tam may play an estrogen-like role in promoting tumor growth after patients acquire breast cancer with Tam resistance. Therefore, to ensure a safe dose range, a relatively high level of Tam is better for the control of disease and delays the progression to Tam-resistant breast cancer. In order to confirm our data and hypothesis, and more importantly to provide a powerful conclusion to the standardized use of Tam, a large-scale epidemiological survey should be implemented to identify the differences in the survival rates and disease progression in different Tam concentration groups. If possible, the optimal dosage of Tam should be identified by further investigation as soon as possible to delay the occurrence of the Tam resistance, even to overcome the Tam resistance.

In summary, we describe a novel phenomenon that different doses of Tam have exactly opposite effects on TAM-R cells and identified a previously unappreciated role of high-dose Tam which has significant anti-proliferative effect on TAM-R cells. More importantly, we found that the phosphorylation of ERK1/2 and AKT may play an important role in this process. Further research is warranted to identify the molecular targets of high doses of Tam, and the practical implications that may be derived from these data. First, clinical workers should strictly avoid the stimulating effects of low-dose Tam for Tam-resistant patients in clinical application, as low-dose Tam does not block tumor growth but instead may accelerate disease progression. Second, the special anti-proliferative effect of high-dose Tam on TAM-R cells should be investigated and considered as a breakthrough point in the mechanistic study of Tam resistance. More studies must be carried out to further 
confirm the disadvantages of the application of low-dose Tam for Tam-resistant patients and assess the feasibility of highdose Tam therapy for Tam-resistant patients.

\section{Acknowledgements}

This work was financially supported by National Natural Science Foundation of China (81072117).

\section{References}

1. Tamoxifen for early breast cancer: an overview of the randomised trials. Early Breast Cancer Trialists' Collaborative Group. Lancet 351: 1451-1467, 1998.

2. Powles TJ, Ashley S, Tidy A, Smith IE and Dowsett M: Twentyyear follow-up of the Royal Marsden randomized, double-blinded tamoxifen breast cancer prevention trial. J Natl Cancer Inst 99: 283-290, 2007.

3. Cuzick J, Powles T, Veronesi U, et al: Overview of the main outcomes in breast-cancer prevention trials. Lancet 361: 296-300, 2003.

4. Kurebayashi J: Resistance to endocrine therapy in breast cancer. Cancer Chemother Pharmacol 56 (Suppl 1): 39-46, 2005.

5. Campbell RA, Bhat-Nakshatri P, Patel NM, Constantinidou D, Ali S and Nakshatri H: Phosphatidylinositol 3-kinase/ AKT-mediated activation of estrogen receptor alpha: a new model for anti-estrogen resistance. J Biol Chem 276: 9817-9824, 2001.

6. Gee JM, Robertson JF, Ellis IO and Nicholson RI: Phosphorylation of ERK1/2 mitogen-activated protein kinase is associated with poor response to anti-hormonal therapy and decreased patient survival in clinical breast cancer. Int J Cancer 95: 247-254, 2001

7. Ignatov A, Ignatov $\mathrm{T}$, Weissenborn $\mathrm{C}$, et al: G-protein-coupled estrogen receptor GPR 30 and tamoxifen resistance in breast cancer. Breast Cancer Res Treat 128: 457-466, 2011.

8. Miller TW, Balko JM and Arteaga CL: Phosphatidylinositol 3-kinase and antiestrogen resistance in breast cancer. J Clin Oncol 29: 4452-4461, 2011.

9. Brunner N, Frandsen TL, Holst-Hansen C, et al: MCF7/LCC2: a 4-hydroxytamoxifen resistant human breast cancer variant that retains sensitivity to the steroidal antiestrogen ICI 182,780. Cancer Res 53: 3229-3232, 1993.

10. Ignatov A, Ignatov T, Roessner A, Costa SD and Kalinski T: Role of GPR30 in the mechanisms of tamoxifen resistance in breast cancer MCF-7 cells. Breast Cancer Res Treat 123: 87-96, 2010.

11. Shou J, Massarweh S, Osborne CK, et al: Mechanisms of tamoxifen resistance: increased estrogen receptor-HER2/neu cross-talk in ER/HER2-positive breast cancer. J Natl Cancer Inst 96: 926-935, 2004

12. Benz CC, Scott GK, Sarup JC, et al: Estrogen-dependent, tamoxifen-resistant tumorigenic growth of MCF-7 cells transfected with HER2/neu. Breast Cancer Res Treat 24: 85-95, 1992.

13. Ward A, Balwierz A, Zhang JD, et al: Re-expression of microRNA-375 reverses both tamoxifen resistance and accompanying EMT-like properties in breast cancer. Oncogene: Apr. 16, 2012 (Epub ahead of print).

14. Hurtado A, Holmes KA, Geistlinger TR, et al: Regulation of ERBB2 by oestrogen receptor-PAX2 determines response to tamoxifen. Nature 456: 663-666, 2008.

15. Britton DJ, Hutcheson IR, Knowlden JM, et al: Bidirectional cross talk between ERalpha and EGFR signalling pathways regulates tamoxifen-resistant growth. Breast Cancer Res Treat 96: 131-146, 2006

16. Clark AS, West K, Streicher S and Dennis PA: Constitutive and inducible Akt activity promotes resistance to chemotherapy, trastuzumab, or tamoxifen in breast cancer cells. Mol Cancer Ther 1: 707-717, 2002.

17. Gerits N, Kostenko S, Shiryaev A, Johannessen M and Moens U: Relations between the mitogen-activated protein kinase and the cAMP-dependent protein kinase pathways: comradeship and hostility. Cell Signal 20: 1592-1607,2008.

18. Liu AM, Lo RK, Wong CS, Morris C, Wise H and Wong YH: Activation of STAT3 by $\mathrm{G}$ alpha(s) distinctively requires protein kinase A, JNK, and phosphatidylinositol 3-kinase. J Biol Chem 281: 35812-35825, 2006.
19. Selever J, Gu G, Lewis MT, et al: Dicer-mediated upregulation of BCRP confers tamoxifen resistance in human breast cancer cells. Clin Cancer Res 17: 6510-6521, 2011.

20. Schafer JM, Bentrem DJ, Takei H, Gajdos C, Badve S and Jordan VC: A mechanism of drug resistance to tamoxifen in breast cancer. J Steroid Biochem Mol Biol 83: 75-83, 2002.

21. Wiebe VJ, Osborne CK, Fuqua SA and DeGregorio MW: Tamoxifen resistance in breast cancer. Crit Rev Oncol Hematol 14: 173-188, 1993.

22. Clarke R, Liu MC, Bouker KB, et al: Antiestrogen resistance in breast cancer and the role of estrogen receptor signaling. Oncogene 22: 7316-7339, 2003.

23. Schwartz JL, Shajahan AN and Clarke R: The role of interferon regulatory factor-1 (IRF1) in overcoming antiestrogen resistance in the treatment of breast cancer. Int J Breast Cancer 2011: 912102, 2011.

24. Zhou C, Zhong Q, Rhodes LV, et al: Proteomic analysis of acquired tamoxifen resistance in MCF-7 cells reveals expression signatures associated with enhanced migration. Breast Cancer Res 14: R45, 2012.

25. Canney PA, Griffiths T, Latief TN and Priestman TJ: Clinical significance of tamoxifen withdrawal response. Lancet 1: 36 , 1987.

26. Howell A, Dodwell DJ, Anderson H and Redford J: Response after withdrawal of tamoxifen and progestogens in advanced breast cancer. Ann Oncol 3: 611-617, 1992.

27. Banerjee S, Kambhampati S, Haque I and Banerjee SK: Pomegranate sensitizes tamoxifen action in ER-alpha positive breast cancer cells. J Cell Commun Signal 5: 317-324, 2011.

28. Leung E, Kannan N, Krissansen GW, Findlay MP and Baguley BC: MCF-7 breast cancer cells selected for tamoxifen resistance acquire new phenotypes differing in DNA content, phospho-HER 2 and PAX2 expression, and rapamycin sensitivity. Cancer Biol Ther 9: 717-724, 2010.

29. deGraffenried LA, Friedrichs WE, Russell DH, et al: Inhibition of mTOR activity restores tamoxifen response in breast cancer cells with aberrant Akt Activity. Clin Cancer Res 10: 8059-8067, 2004.

30. Vivacqua A, Bonofiglio D, Recchia AG, et al: The G proteincoupled receptor GPR30 mediates the proliferative effects induced by 17beta-estradiol and hydroxytamoxifen in endometrial cancer cells. Mol Endocrinol 20: 631-646, 2006.

31. Carmeci C, Thompson DA, Ring HZ, Francke U and Weigel RJ: Identification of a gene (GPR30) with homology to the G-proteincoupled receptor superfamily associated with estrogen receptor expression in breast cancer. Genomics 45: 607-617, 1997.

32. Filardo EJ, Graeber CT, Quinn JA, et al: Distribution of GPR30, a seven membrane-spanning estrogen receptor, in primary breast cancer and its association with clinicopathologic determinants of tumor progression. Clin Cancer Res 12: 6359-6366, 2006.

33. Li Y, Birnbaumer L and Teng CT: Regulation of ERRalpha gene expression by estrogen receptor agonists and antagonists in SKBR3 breast cancer cells: differential molecular mechanisms mediated by g protein-coupled receptor GPR30/GPER-1. Mol Endocrinol 24: 969-980, 2010.

34. Kleuser B, Malek D, Gust R, Pertz HH and Potteck H: 17-Betaestradiol inhibits transforming growth factor-beta signaling and function in breast cancer cells via activation of extracellular signal-regulated kinase through the $\mathrm{G}$ protein-coupled receptor 30. Mol Pharmacol 74: 1533-1543, 2008.

35. Massarweh S, Osborne CK, Creighton CJ, et al: Tamoxifen resistance in breast tumors is driven by growth factor receptor signaling with repression of classic estrogen receptor genomic function. Cancer Res 68: 826-833, 2008.

36. Hutcheson IR, Knowlden JM, Madden TA, et al: Oestrogen receptor-mediated modulation of the EGFR/MAPK pathway in tamoxifen-resistant MCF-7 cells. Breast Cancer Res Treat 81: 81-93, 2003.

37. Zheng B, Lavoie C, Tang TD, et al: Regulation of epidermal growth factor receptor degradation by heterotrimeric Galphas protein. Mol Biol Cell 15: 5538-5550, 2004.

38. Stryjek-Kaminska D, Piiper A and Zeuzem S: Epidermal growth factor regulates adenylate cyclase activity via Gs and Gi1-2 proteins in pancreatic acinar membranes. Biochem J 316: 87-91, 1996.

39. Maggiolini M and Picard D: The unfolding stories of GPR30, a new membrane-bound estrogen receptor. J Endocrinol 204: 105-114, 2010.

40. Huiart L, Dell'Aniello S and Suissa S: Use of tamoxifen and aromatase inhibitors in a large population-based cohort of women with breast cancer. Br J Cancer 104: 1558-1563, 2011. 